\title{
Perinatal death in ethnic minorities in the Netherlands
}

Adam van Enk, Simone E Buitendijk, Karin M van der Pal, Willem J J van Enk, Tom W J Schulpen

\begin{abstract}
Objectives-To investigate differences in perinatal death rate and associated obstetric risk factors between ethnic groups in the Netherlands.
\end{abstract}

Design-Retrospective cohort study based on the 1990-1993 birth cohorts in the National Obstetric Registry.

Subjects-569 743 births of which 85527 were for women belonging to ethnic minorities.

Main outcome measures-Perinatal death occurring between 16th week of pregnancy and 24 hours after birth.

Method-Bivariate and multivariate analysis of perinatal death rate per ethnic group. A total of 42282 women living in the three main cities of the Netherlands were classified on the basis of postal code districts into four socioeconomic (SES) classes for analysis of the relation between SES, perinatal death, and preterm birth. Results-Black mothers had the highest perinatal death rate compared with indigenous Dutch (odds ratio $2.2,95 \%$ CI 1.9 , 2.4) followed by a group "others", consisting of women of mixed or unknown ethnicity (odds ratio $1.8,95 \%$ CI $1.5,2.0$ ), Hindustani (odds ratio $1.4,95 \%$ CI 1.2 , 1.6), and Mediterraneans (odds ratio 1.3, 95\%CI 1.2, 1.4). Asians (excluding West Indian Asians) and non-Dutch Europeans did not have higher rates than Dutch women. The increased rates of black and Hindustani women could be explained fully and that of the group "others" partially by higher rates of preterm birth. Controlling for age and parity lowered the odds ratio of the Mediterraneans slightly. The risk of ethnicity was independent of SES.

Conclusion-Ethnic minorities in the Netherlands except immigrants from Asia and other European countries have higher rates of perinatal death than indigenous Dutch women. With a twofold increase, black women had the highest rate, which was related to an equally large increased rate of preterm birth.

(F Epidemiol Community Health 1998;52:735-739)

Centre for Migration and Child Health, Wilhelmina Children's Hospital, Utrecht, the Netherlands

T W J Schulpen

Correspondence to:

Dr A van Enk.

Accepted for publication 1 June 1998

Differences in perinatal death rates between social and ethnic groups have been reported from many countries. They are often ascribed to socioeconomic factors or to inequalities of medical care. In many instances, however, there is no clear cut explanation.
Since the sixties the Netherlands have had a relatively large ethnic minority amounting to just over $6 \%$ of the population. Its composition differs from those of surrounding countries. Unlike the United Kingdom the largest group originates from Islamic Mediterranean countries, chiefly Turkey and Morocco, and unlike Belgium and Germany the second largest group comes from South America (Surinam) and the Caribbean, comprising both black and Hindustani. The rest is of various ethnic and geographical origin, such as Indonesia (the former Dutch East Indies) and other European countries. ${ }^{1}$

Ethnicity seemed to influence perinatal death rates among hospital delivered women in Amsterdam in the seventies. ${ }^{2}$ Whether that was also the case in the country as a whole and applicable to women delivering at home was unknown.

The introduction of a nationwide obstetric registry scheme that also records ethnicity enabled us to conduct a study of perinatal death in home and hospital births on a national basis.

The object of the study was to examine whether differences existed and if so, whether they were associated with obstetric risk factors (where these were recorded in the registry) as well as to identify or suggest ways to reduce the differences.

\section{Methods}

POPULATION

To study differences in perinatal mortality among different ethnic groups in the Netherlands data from the Dutch National Perinatal Registry (LVR=Landelijke Verloskundige Registratie) were used. The LVR is a (voluntary) registry to which participating midwives and gynaecologists send data on women and newborns after delivery at home or in hospital. The last care provider completes the forms and sends the data to the LVR-1 (for midwives) or to the LVR-2 (for gynaecologists). In 1993, $88 \%$ of the total number of births in midwife practices and $87 \%$ of the total number of births attended by obstetricians was recorded in the appropriate LVR. The participation of general practitioners in the LVR is very low (as it is in obstetric care). In total, $83 \%$ of all births in 1993 were registered in the LVR. ${ }^{3}$

Our data analysis is based on all singleton 
women it was decided to reduce the number of singleton pregancies of Dutch women. At random two Dutch women for each nonDutch woman were selected $(n=171054)$. The reduction of the total number of Dutch women does not reduce the statistical power of the analysis.

Obviously, our analysis was restricted to the set of available data. Important factors in perinatal death as drug use, hypertension or anaemia could therefore not be studied.

\section{DATA ANALYSIS}

Variables

Perinatal death in the LVR is defined as death occurring after the 16 th week of gestation until seven days after birth. There are five different categories. The first includes perinatal death between 16 weeks of gestation until 28 weeks of gestation. The second category consists of perinatal death occurring after 28 completed weeks of gestation. Perinatal death that occurs during labour is registered in the third category. The fourth category includes perinatal death within the first 24 hours after birth and the last category consists of perinatal deaths between 24 hours and 168 hours after birth. As the registration forms are usually completed soon after discharge of the mother from hospital, perinatal death after the first 24 hours is poorly registered and is therefore not included in this study.

In the LVR the ethnicity of the women is registered on the basis of ethnic and geographical background. Ethnicity is divided into seven categories: Dutch, Mediterranean, Black, Hindustani, Asian, non-Dutch European, and "others". Dutch women are defined as born in the Netherlands and of west European origin. The group Mediterranean consists of Turkish and North-African (mainly Moroccan) women. Most of the black women have their origins in Surinam and the Dutch Antilles. The Hindustani are West Indian Asian women, from Surinam, and the Dutch Antilles. The Asian women are mainly Chinese, Malaysian, and Moluccan. The group non-Dutch European women consists of those from Western and Eastern Europe. The group "others" comprises women with
KEY POINTS

- Ethnic minorities in the Netherlands except immigrants from Asia and other European countries have higher rates of perinatal death than indigenous Dutch women. With a twofold increase, black women had the highest rate, which was related to an equally large increased rate of preterm birth.

- The difference between the black and the other ethnic communities cannot be explained by socioeconoimic factors.

- The authors suggest that differences in the incidence and nature of vaginal infections between ethnic groups may play an important part and recommend further studies.

mixed, unknown or other ethnicity. The ethnicity of the woman is classified by the care provider.

Women of ethnic minorities tend to have a lower socioeconomic status (SES) than Dutch women. As this may influence the risk of perinatal death, SES was included in the analysis. Women were divided into four categories of SES based on the postal code. The postcode number can be used as a proxy measure for income and rate of unemployment. The first category consists of women living in districts with a low SES, the last category consists of those in a district with a high SES. The SES could only be assessed for women living in Amsterdam, Rotterdam or Utrecht $(n=42$ 282).

\section{Statistical analysis}

Differences in distribution of perinatal death by the variables considered to influence perinatal death as recorded in the LVR among Dutch women and women of the six ethnic groups were tested using the $\chi^{2}$ test. The risk of perinatal death by ethnicity was assessed in logistic regression analyses using three different models. In the first model the influence of SES was analysed. In the second model risk of perinatal death was assessed after correction for maternal age and parity. In

Table 1 Distribution of variables that are considered to influence the risk of perinatal death by ethnic group ${ }^{*}$

\begin{tabular}{|c|c|c|c|c|c|c|c|}
\hline & $\begin{array}{l}\text { Dutch } \\
\%\end{array}$ & $\begin{array}{l}\text { Mediterranean } \\
\%\end{array}$ & $\begin{array}{l}\text { Black } \\
\%\end{array}$ & $\begin{array}{l}\text { Hindus } \\
\%\end{array}$ & Asian & $\begin{array}{l}\text { Other European } \\
\%\end{array}$ & $\begin{array}{l}\text { Others } \\
\%\end{array}$ \\
\hline Maternal age (y) & 170946 & 39378 & 10153 & 8017 & 10393 & 8975 & 7999 \\
\hline$\leqslant 19$ & 1.1 & 12.0 & 6.9 & 4.7 & 2.9 & 4.5 & 5.2 \\
\hline $20-34$ & 87.5 & 78.3 & 80.0 & 86.5 & 81.4 & 80.5 & 81.1 \\
\hline$\geqslant 35$ & 11.4 & 9.8 & 13.1 & 8.8 & 15.7 & 15.1 & 13.7 \\
\hline Parity (children) & 170929 & 39885 & 10169 & 8028 & 10395 & 8976 & 8004 \\
\hline 1 & 46.6 & 39.1 & 39.3 & 41.3 & 46.5 & 49.3 & 42.3 \\
\hline $2-4$ & 51.8 & 49.0 & 54.6 & 54.4 & 50.6 & 48.3 & 51.4 \\
\hline$\geqslant 5$ & 1.6 & 11.9 & 6.1 & 4.2 & 2.8 & 2.4 & 5.8 \\
\hline Duration of pregnancy (weeks) & 167660 & 37439 & 9825 & 7817 & 10000 & 8669 & 7711 \\
\hline $16-27$ & 0.9 & 1.2 & 2.7 & 1.4 & 1.0 & 1.1 & 1.4 \\
\hline $28-36$ & 6.4 & 6.4 & 9.5 & 8.1 & 6.6 & 6.1 & 6.8 \\
\hline$\geqslant 37$ & 92.7 & 92.4 & 87.9 & 90.5 & 95.3 & 92.7 & 93.0 \\
\hline Socioeconomic status $†$ & 12414 & 14865 & 1796 & 5776 & 3181 & 1859 & 2391 \\
\hline very low & 21.1 & 42.6 & 39.3 & 37.5 & 37.5 & 31.2 & 38.6 \\
\hline low & 23.6 & 28.4 & 32.3 & 31.2 & 31.2 & 29.0 & 30.8 \\
\hline moderate & 27.0 & 17.0 & 14.8 & 14.8 & 14.8 & 20.8 & 15.6 \\
\hline high & 28.3 & 12.1 & 13.6 & 13.6 & 16.4 & 18.9 & 15.0 \\
\hline
\end{tabular}

${ }^{\star}$ Because of missing values the total numbers per characteristic are not the same. $†$ The distribution of socioeconomic status is only based on women who live in the three major cities of the Netherlands (Amsterdam, Utrecht, Rotterdam). 
Table 2 Distribution of perinatal death by ethnic groups

\begin{tabular}{|c|c|c|c|c|c|c|c|}
\hline & Dutch & Mediterranean & Black & Hindustani & Asian & $\begin{array}{l}\text { Other } \\
\text { European }\end{array}$ & Others \\
\hline \multicolumn{8}{|l|}{ Perinatal death } \\
\hline$<28$ weeks of gestation & 0.6 & 0.7 & 1.1 & 0.8 & 0.6 & 0.5 & 1.0 \\
\hline$\geqslant 28$ weeks of gestation & 0.5 & 0.5 & 0.7 & 0.6 & 0.4 & 0.5 & 0.7 \\
\hline during labour & 0.2 & 0.4 & 0.8 & 0.3 & 0.3 & 0.5 & 0.5 \\
\hline within 24 hour after birth & 0.2 & 0.4 & 0.7 & 0.4 & 0.3 & 0.3 & 0.5 \\
\hline Total & 1.5 & 2.0 & 3.4 & 2.1 & 1.5 & 1.7 & 3.1 \\
\hline
\end{tabular}

Data shown as percentages.

Table 3 Crude and adjusted odds ratios (OR) for perinatal death

\begin{tabular}{llll}
\hline \multicolumn{4}{c}{ Perinatal death } \\
\cline { 2 - 4 } & $\begin{array}{l}\text { Crude OR } \\
(95 \% \text { CI })\end{array}$ & $\begin{array}{l}\text { Adjusted } \\
(95 \% \text { OR })\end{array}$ & $\begin{array}{l}\text { Adjusted } \text { OR } \\
(95 \% \text { CI })\end{array}$ \\
\hline Dutch & 1.0 & 1.0 & 1.0 \\
Mediterranean & $1.3(1.2,1.4)$ & $1.2(1.1,1.3)$ & $1.2(1.1,1.4)$ \\
Black & $2.2(1.9,2.4)$ & $2.1(1.8,2.3)$ & $1.0(0.9,1.2)$ \\
Hindustani & $1.4(1.2,1.6)$ & $1.4(1.2,1.6)$ & $1.1(0.9,1.3)$ \\
Asian & $1.0(0.9,1.2)$ & $1.0(0.9,1.2)$ & $1.0(0.8,1.3)$ \\
Other European & $1.1(0.9,1.3)$ & $1.0(0.9,1.2)$ & $1.0(0.8,1.3)$ \\
Other & $1.8(1.5,2.0)$ & $1.7(1.4,1.9)$ & $1.3(1.1,1.6)$ \\
\hline
\end{tabular}

*Adjusted for maternal age and parity. †Adjusted for maternal age, parity, and preterm birth.

the last model perinatal death adjusted for preterm birth was added. The crude and adjusted odds ratios with $95 \%$ confidence intervals are presented.

\section{Results}

Table 1 presents the distribution of maternal age, parity, duration of pregnancy, and SES for Dutch women and the ethnic groups. Teenage pregnancy and grande multiparity are most frequent among Mediterraneans. Preterm birth is more common among black women. The SES of all ethnic groups is lower compared with the Dutch women. This is most pronounced for Mediterranean, black, and Hindustani women.

Table 2 shows the incidence of perinatal death for Dutch women and the women of ethnic minorties. Perinatal death occurred most frequently among black women (3.4\%) especially before 28 weeks of gestation. Among other European and Asian women the perinatal death rate was comparable to that of Dutch women.

The distribution of maternal age, parity, duration of pregnancy, and SES differed between Dutch women and those of the ethnic minority groups. These factors may influence the incidence of perinatal death. The influence of SES could only be assessed on a subsample of the population.

Table 4 Crude and adjusted odds ratios $(O R)$ for perinatal death and preterm birth per ethnic group in the SES coded sample ( $n=42$ 282)

\begin{tabular}{|c|c|c|c|c|}
\hline & \multicolumn{2}{|l|}{ Perinatal death } & \multicolumn{2}{|l|}{ Preterm birth } \\
\hline & $\begin{array}{l}\text { Crude OR } \\
(95 \% \text { CI) }\end{array}$ & $\begin{array}{l}\text { Adjusted OR* } \\
(95 \% C I)\end{array}$ & $\begin{array}{l}\text { Crude OR } \\
\text { (95\% CI) }\end{array}$ & $\begin{array}{l}\text { Adjusted OR } \\
(95 \% \mathrm{CI})\end{array}$ \\
\hline Dutch & 1.0 & 1.0 & 1.0 & 1.0 \\
\hline Mediterranean & $1.2(1.0,1.4)$ & $1.1(0.9,1.4)$ & $1.0(0.9,1.1)$ & $0.9(0.8,1.0)$ \\
\hline Black & $2.0(1.6,2.4)$ & $2.0(1.6,2.4)$ & $1.6(1.4,1.8)$ & $1.6(1.4,1.7)$ \\
\hline Hindustani & $1.2(0.9,1.6)$ & $1.3(1.0,1.7)$ & $1.2(1.0,1.4)$ & $1.2(1.0,1.4)$ \\
\hline Asian & $1.2(0.8,1.7)$ & $1.2(0.8,1.7)$ & $1.0(0.8,1.2)$ & $1.0(0.8,1.2)$ \\
\hline Other European & $0.9(0.6,1.4)$ & $0.9(0.6,1.3)$ & $1.0(0.8,1.2)$ & $0.9(0.6,1.1)$ \\
\hline Other & $1.5(1.1,1.9)$ & $1.4(1.1,1.9)$ & $1.3(1.1,1.5)$ & $1.3(1.1,1.5)$ \\
\hline
\end{tabular}

^Adjusted for SES, parity, and age.
Table 3 shows the crude odds ratio and adjusted odds ratio for perinatal death. Considering the crude odds ratios only, perinatal death occurs more often in black mothers than in Dutch mothers. Furthermore, children of Mediterranean and Hindustani women and women of the "others" group had a higher risk of perinatal death than Dutch women. Adjustment for maternal age and parity did not influence the odds ratios substantially. When adjusting for preterm birth, the risk of perinatal death decreased considerably for black women and no longer differed from the risk of perinatal death in Dutch women. The adjusted risk of perinatal death for Mediterrean women and women of the "others" group did not change.

Table 4 presents per ethnic group the crude odds ratio and the odds ratio adjusted for SES of the risk of perinatal death and preterm birth. Adjustment for SES has no influence on the ratios. Data not shown here demonstrate that SES has an (significant) inverse relation with preterm birth (odds ratio for the two lowest categories $1.2,95 \% \mathrm{CI} 1.1,1.3$ ). As for perinatal death, the odds ratio does not reach statistical significance. Adjustement for ethnicity does not change the relation between SES and preterm birth.

\section{Discussion}

This study shows clear differences in perinatal death between ethnic groups. Blacks have the highest rate, followed by the group "others", which comprises many of mixed ethnic backgrounds. Although in the national obstetric registry (LVR) only $83 \%$ of all births were registered in the period we studied, this is unlikely to bias our results. The incompleteness is because not all obstetricians, midwives, and general practitioners take part in the LVR and not because of selective recording practices. Even if there were an underrepresentation or overrepresentation of ethnic minorities in the registry, it would in all probability not influence our conclusions.

The differences in perinatal mortality can be explained for black and Hindustani women fully and for the "others" to a large degree by the high incidence of (very early) preterm birth. In Mediterraneans the (moderately) raised risk depends partially on sociodemographic characteristics such as teenage pregnancy and grande multiparity.

It has also been reported in the USA that perinatal mortality and preterm birth in black women is about two times higher than in a white population, Chinese, and South East Asians and also higher, though in varying 
degree, than in immigrants from the Indian subcontinent and South or Middle America respectively. ${ }^{45}$

As the black population in the USA is socioeconomically much less well off than the white population, it was tempting (and for some time politically correct) to ascribe the poorer obstetric outcome of the former to social circumstances. However, in several more recent studies it could been shown that differences persisted after correction for SES. ${ }^{6}$ It was also reported that recently arrived and socially disadvantaged Spanish speaking Mexican women had a perinatal and neonatal death rate similar to non-Hispanic white women and half that of American black women. ${ }^{4}$

We have also tried to weigh the impact of the SES on the differences in perinatal mortality and preterm birth (in a subsample comprising about one sixth of the study population). A relation seemed to exist between preterm delivery and SES but it was independent of ethnicity and did not explain the differences. The relation between SES and perinatal death did not reach statistical significance.

We recognise that caution is warranted as regards the use of the SES derived from postal area codes. It is obvious that not all those sharing the same postal code have the same SES. Nevertheless a relation between the SES as we used it and morbidity and mortality patterns have been demonstrated. ${ }^{7}$ Such a relation also existed in our study population. The lower the SES, the higher the risk of preterm labour, indicating that this measure of socioeconomic well being is relevant.

There is also other, though indirect evidence supporting the notion that socioeconomic factors are not reponsible for the differences.

A similar pattern of differences was found among 27813 hospital delivered women in Amsterdam in the seventies. ${ }^{2}$ Black women had the highest perinatal death rate: $1.8,1.6$, and 1.5 higher than respectively Dutch, Asian (including Hindustani), and Mediterranean women. The difference with the Dutch group was caused by an almost twofold increased rate of preterm birth among black women.

Certainly at that time black immigrants from Surinam and the Antilles had clear social advantages over other immigrant groups especially the Mediterraneans. All black immigrants from Dutch speaking West Indies had attended primary schools (where Dutch standards prevailed) and many had much more schooling than that. The Dutch social and medical system was familiar to them and it could be shown that they made more frequent use of obstetric services than Mediterranean women, most of whom did not speak Dutch and were illiterate. ${ }^{2}$ Although Mediterraneans have now much less trouble in finding their way in the Dutch social and medical care system, recent figures show that the black population are still doing better than Mediterraneans in the field of schooling and employment. ${ }^{18}$

Another finding that does not support the socioeconomic explanation is that the black- white ratio in preterm birth and perinatal mortality in the Netherlands is about the same as in the USA. ${ }^{49}$ The two countries have different social and health care systems. The socioeconomic conditions of the black communities differ. Inner city problems on the scale of the USA are unknown in the Netherlands. There is little segregration between black and white populations in contrast with Mediterraneans and Dutch. ${ }^{1}$ Health care is to the same extent available to all ethnic and social groups. LVR data show that pregnant black women "consume" more specialist or hospital centered care than women of other ethnic groups, including Dutch women (data not presented).

These findings show that differences in obstetric outcome between ethnic groups cannot simply be explained by socioeconomic factors and inequalities in health care and that other explanations have to be looked for.

Recently indications have been found in the USA that the difference in preterm birth rate between white and black women is related to a higher rate of bacterial vaginosis and genital infections. ${ }^{10-12}$ The causes are not clear. It can only partially be ascribed to sexual behaviour. ${ }^{13}$ Studies on the epidemiology of bacterial vaginosis have not been done in Holland. It has however been established that the incidence of genital infections is much higher among black immigrants than among indigenous Dutch women and other ethnic groups. ${ }^{14}$

We also observed increased perinatal death associated with increased preterm birth rate among the group of Hindustani and "others" (comprising those of mixed race), though much less pronounced. As sections of these groups have lived in the countries of origin closely with the black community, it could be hypothesised that they share risk factors related to common life style, behaviourial patterns or health care habits.

It is clear that strategies to reduce the interethnic differences in perinatal death in the Netherlands should focus primarily on preterm birth among the black population. It is however far from clear what form they should take. There are no reasons to assume that black women receive inadequate or insufficient obstetric care. LVR data show that black women do not book later for antenatal care than ethnic Dutch women and that their hospital delivery rate is higher (data not presented). If indeed, bacterial vaginosis and genital infections are mainly to blame for the high rate of preterm birth and consequently of perinatal death in the black community, as seems to be the case in the USA, ${ }^{12}$ effective means to reduce the differences with other ethnic groups are available..$^{15}$ However, studies on the prevalence of bacterial vaginosis and its relation with ethnicity have still to be done in the Netherlands.

Funding: the study was financially supported by the Ministry of Health, Welfare and Sports and the foundation SKWOSZ (Stichting Klinisch Wetenschappelijk Onderzoek Slotervaartziekenhuis).

Conflicts of interest: none. 
1 Tesser PTM, van Dugteren FA, Merens A. Report Minorities 1996. Population, employment, education, housing. [In Dutch]. 1996. Population, employment, education, housing. [In

2 Doornbos JPR, Nordbeck HJ. Perinatal mortality. Obstetric risk factors in a community of mixed ethnic origin in Amsterdam. [Dissertation]. Amsterdam: University of Amsterdam, 1985

3 SIG zorginformatie. Participation in percentages LVR1 and LVR2. In: SIG health care information. Obstetrics in the Netherlands. Trends 1989-1993. Appendix A3. [In Dutch] Utrecht: Sig zorginformatie, 1996.

4 Blackmore CA, Savitz DA, Sioban D, et al. Racial difference in the patterns of preterm delivery in central North Carolina, USA. Paediatr Perinat Epidemiol 1995;9:281-95.

5 Shiono PH, Klebanoff MA. Ethnic differences in preterm and very preterm delivery. Am F Public Health 1986;76: 1317-21.

6 Parker JD, Schoendorf KC, Keily JL. Associations between measures of socioeconomic status and low birthweight, small for gestational age and premature delivery in the Small for gestational age and premature

7 Haverkate I, Reyneveld SA, Oers JAM, et al. Mortality per resident area in socio-economic status. Comparison between the largest Dutch cities. [In Dutch]. Amsterdam: Municipal Health Service, 1993.
8 Berdowski Z. Annual report 1994. Ethnic groups in Amsterdam. [In Dutch]. Amsterdam: Bureau for Minority Amsterdam. [In Dutch

policies 1994: $37-47$.
9 Sherman AJ. Racial and ethnic differences in infant mortality and low birthweight. Ann Epidemiol 1993;3:130-6.

10 Goldenberg RL, Klebanoff MA, Nugent R, et al. Bacterial colonisation of the vagina during pregnancy in four ethnic groups. Am f Obstet Gynecol 1996;174:1618-21.

11 Hillier SL, Nugent RP, Eschenbach DA, et al. Association between bacterial vaginosis and preterm delivery of low birth weight infant. N Engl f Med 1995;333:1737-42.

12 Fiscella K. Racial disparities in preterm birth. The role of urogenital infections. Public Health Rep 1996;111:104-13.

13 Moran JS, Aral SO, Jenkins WC, et al. The impact of sexually transmitted diseases on minority populations. Public Health Rep 1989;104:560-5.

14 Hooykaas C, van der Velde FW, van der Linden MM, et al. The importance of ethnicity as a risk factor for STDs and sexual behaviour among heterosexuals. Genitourin Med 1991;67:378-83.

15 Hauth JC, Goldenberg RL, Andrews WW, et al. Reduced incidence of preterm delivery with metronidazole and erythromycine in women with bacterial vaginosis. N Engl f Med 1995;333:1732-6. 